\title{
Cephalic Vein Cut-down for Totally Implantable Central Venous Access Devices With Preoperative Ultrasonography by Surgical Residents
}

\author{
SHINTARO HASHIMOTO ${ }^{1,2}$, RYOTA OTSUBO ${ }^{2}$, MASAHIRO ADACHI ${ }^{1}$, \\ RYOICHIRO DOI ${ }^{1}$, KENICHIRO SHIBATA ${ }^{1}$, ISAO SANO ${ }^{1}$, YOSHIHITO SHIBATA ${ }^{1}$, \\ TAKAYUKI NAKAZAKI ${ }^{1}$, HIDEKI TANIGUCHI $^{1}$ and TAKESHI NAGAYASU ${ }^{2}$ \\ ${ }^{1}$ Department of Surgery, Japanese Red Cross Nagasaki Genbaku Hospital, Nagasaki, Japan; \\ ${ }^{2}$ Department of Surgical Oncology, Nagasaki University Graduate School of Biomedical Sciences, Nagasaki, Japan
}

\begin{abstract}
Background/Aim: Cephalic vein (CV) cut-down for totally implantable central venous access devices (TICVADs) is not frequently used due to its low success rate. We compared the outcomes of CV cut-down using preoperative ultrasonography (US) performed by experienced surgeons versus surgical residents. Patients and Methods: From December 2015 to December 2017, 10 surgeons implanted 212 TICVADs using CV cut-down with preoperative US. The surgeons were divided into two groups of five each: surgical residents (Group A, $n=124$ procedures) and experienced surgeons (Group B, $n=88$ procedures). Duration of operation time, completion rate, and complications were retrospectively analyzed. Results: The completion rate was significantly higher in Group A (98.4\% versus $92.0 \%, p=0.04)$. Duration of operation time $(45.2 \pm 14.5$ versus $42.0 \pm 13.1$ minutes, $p=0.22)$, rates of early complications (1.6\% versus $1.1 \%$, $p=0.77)$ and late complications (3.2\% versus $2.3 \%, p=0.68)$ were equivalent between the two groups. No fatal complications occurred in either group. Conclusion: $C V$ cutdown can be safely performed by surgical residents under the use of preoperative US.
\end{abstract}

Totally implantable central venous access devices (TICVADs) are used in patients who require long-term therapy and nutritional support for oncologic or other

This article is freely accessible online.

Correspondence to: Ryota Otsubo, Department of Surgical Oncology, Nagasaki University Graduate School of Biomedical Sciences, 1-7-1 Sakamoto, Nagasaki 852-8501, Japan. Tel: +81 95 8197304, Fax: +81958197304, e-mail: rotsubo@nagasaki-u.ac.jp

Key Words: CV cut-down, totally implantable central venous access device, surgical education, ultrasonography, cephalic vein. diseases (1). The most frequently used veins for placement of TICVADs are the internal jugular vein (IJV) and subclavian vein (SV), using the Seldinger technique with or without ultrasonography (US); however, these approaches can cause complications, including pneumothorax, hemothorax, and arterial injury (2-6).

Cephalic vein (CV) cut-down (2-4, 7-12), in addition to external jugular vein (EJV) cut-down $(5,6,13)$ for TICVADs, is reportedly safe with a lower fatal complication rate. However, $\mathrm{CV}$ cut-down is associated with a low completion rate $(82 \%-97 \%)(2,4,6-9,11,12)$, technical limitations (9), and a requirement for more advance surgical expertise (10).

We have previously reported the usefulness of preoperative US in terms of shortening the duration of operation time and increasing the completion rate in TICVAD implantation, using the CV cut-down technique (2). Following that study, we used CV cut-down as the firstchoice technique and performed preoperative US for all TICVAD implantation procedures with the CV cut-down approach. Although surgical residents perform TICVAD implantations with CV cut-down in our institution, only few reports have described the outcomes of TICVAD implantation with $\mathrm{CV}$ cut-down performed by surgical residents. The present study was performed to compare the safety and surgical outcomes of CV cut-down for TICVAD implantation performed by surgical residents versus experienced surgeons.

\section{Patients and Methods}

This retrospective study was approved by the institutional review board of our hospital, and the requirement for informed consent was waived. The ethics approval number was 537.

From December 2015 to December 2017, we implanted 371 TICVADs in 367 patients at The Japanese Red Cross Nagasaki Genbaku Hospital. We excluded 156 TICVADs from 152 patients 
whose existing central vein catheters had been used as replacements and 3 TICVADs in 3 patients who had undergone implantation using the IJV puncture approach because their CVs were unsuitable for cut-down. Finally, we analyzed the outcomes of 212 TICVAD implantation procedures in 212 patients using $\mathrm{CV}$ cut-down in the present study.

We divided the surgeons into two groups of five each: i) surgical residents (3-5 years following graduation; Group A, n=124 procedures) and ii) experienced surgeons ( $>10$ years following graduation; Group $\mathrm{B}, \mathrm{n}=88$ procedures). No surgeons in Group A were board-certified surgeons, and all surgeons in Group B were board-certified surgeons. Operation data including i) the completion rate, ii) the duration of operating time, and iii) the complication rate were retrospectively compared between Groups A and B.

Three types of TICVADs were used: i) the open-ended 6.0-Fr single-lumen X-Port ${ }^{\mathrm{TM}}$ isp (Bard Access Systems, Salt Lake City, UT, USA) $[\mathrm{n}=155(73.1 \%)]$, ii) the closed-ended 8.0-Fr single-lumen PowerPort ${ }^{\circledR}$ M.R.I. ${ }^{\circledR}$ isp (Bard Access Systems) [n=30 (14.2\%)], and iii) the closed-ended 8.0-Fr single-lumen MicroNeedle Port (Covidien Japan, Tokyo, Japan) [n=27 (12.7\%)]

Preoperative US. The US and cut-down techniques have been described in our previous report (2) (Figure 1A and B). In all cases, preoperative US was performed to check the depth and diameter of the bilateral $\mathrm{CVs}$ at $3 \mathrm{~cm}$ below the inferior margin of the clavicle immediately before the operation. We also checked the venous convergence of the axillary vein (AV). The $\mathrm{CV}$ is located in the fat pad below the fascia between the deltoid muscle and the major pectoral muscle.

Primary approach of $C V$ cut-down. Skin markings were made along the $\mathrm{CV}$ route (Figure 2), and the operations were then performed in the angiography suite under sterile conditions. Following administration of local anesthesia, a 3- to 6-cm skin incision was made along the skin, marking in the deltopectoral groove in the upper anterior chest wall. The $\mathrm{CV}$ was exposed, ligated distally, and encircled cranially with 3-0 silk (Nescosuture ${ }^{\circledR}$; alfresa, Osaka, Japan). A catheter filled with heparin sodium solution (5,000 IU of heparin (Heparin Sodium 5,000 units $/ 5 \mathrm{~mL}$ for Inj. ${ }^{\circledR}$; MOCHIDA, Tokyo, Japan) in $10 \mathrm{ml}$ of isotonic saline (OTSUKA NORKAL SALINE ${ }^{\circledR}$; Otsuka, Tokyo, Japan) was inserted into the CV through a transverse venotomy with a vein pick.

When the catheter could not be advanced into the central vein, the guidewire technique was used. A 0.064-mm-diameter guidewire (Radifocus ${ }^{\circledR}$; Terumo, Tokyo, Japan) was inserted from the end of the catheter, and if the guidewire was advanced into the central vein, then the catheter was also advanced into the central vein. The tip of the catheter was positioned at the entrance of the right atrium under fluoroscopy. Following cranial ligation with 3-0 silk, the catheter was cut and connected to the reservoir. Using the same skin incision, a subcutaneous pocket was made on the pectoral fascia. The reservoir was fixed to the pectoral fascia with two absorbable sutures. Following skin closure, patency for blood withdrawal and leakage at infusion were tested by cutaneous puncture using a Huber needle enclosed in each device.

Secondary approach of CV cut-down. When the CV was too small we exchanged the device for a smaller open-ended catheter. When a 6.0-Fr open-ended catheter could not be inserted into the CV, either due to the $\mathrm{CV}$ not being found or the guidewire could not be

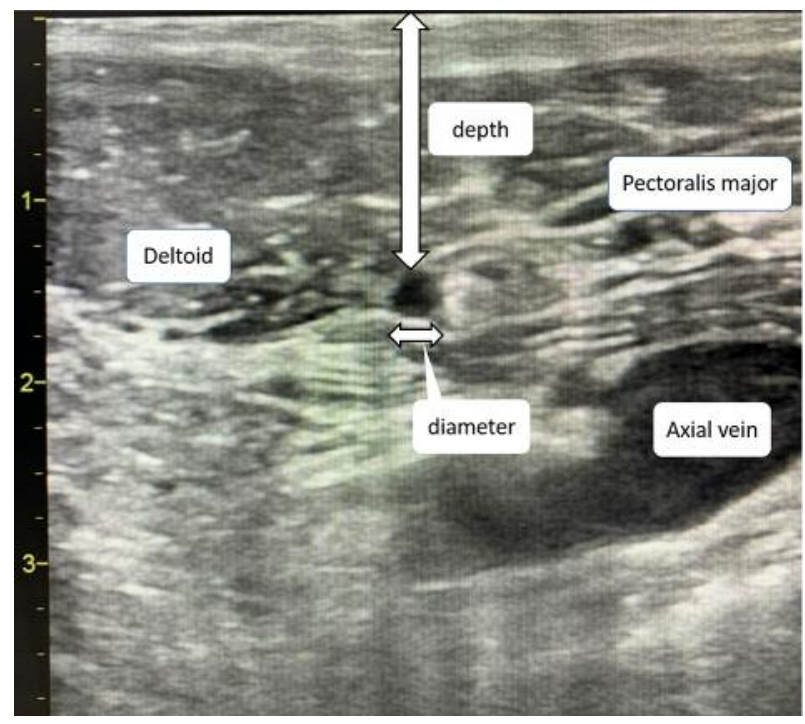

Figure 1. Preoperative ultrasonography to check the depth and diameter of the cephalic vein.

advanced into the central vein, we changed the approach to IJV or SV puncture with real-time US. Even when the approach was changed to IJV or SV puncture, the first incision was used to make a pocket for the reservoir.

A chart review was carried out. The follow-up period ranged from 1 to 952 days in our institution. We evaluated the operation time, completion rate, depth and diameter of the $\mathrm{CV}$ at $3 \mathrm{~cm}$ below the inferior margin of clavicle, convergence of the $\mathrm{AV}$, and complications. We defined early and late complications as those occurring within 7 days and after 8 days, respectively.

Statistical analysis. Continuous data (e.g., age and operating time) are expressed as mean \pm standard deviation, while data representing rare occurrences, such as complications are expressed as a categorical value and percentage in each group. The statistical program JMP 14 (SAS Institute, Inc., Cary, NC, USA) was used to analyze the data. Continuous data were compared using Student's $t$-test, and categorical data were compared using the $\chi^{2}$ test or Fisher's exact test, as appropriate. A $p$-Value of $<0.05$ was considered statistically significant.

\section{Results}

All patients' baseline and preoperative variables were similar between Groups $\mathrm{A}$ and $\mathrm{B}$, including age $(65.3 \pm 11.9$ versus $68.1 \pm 9.4$, years, respectively; $p=0.06$ ), sex (female, $57.0 \%$ versus $40.9 \%$, respectively; $p=0.10$ ), body mass index $\left(21.8 \pm 4.1\right.$ versus $22.6 \pm 4.5 \mathrm{~kg} / \mathrm{m}^{2}$, respectively; $\left.p=0.37\right)$, and the purpose of TICVAD implantation (chemotherapy, $91.9 \%$ versus $92.0 \%$, respectively; $p>0.99$ ). The purpose of TICVAD implantation in most patients was chemotherapy [n=195 (92.0\%)], which was administered for digestive tumors $[n=80(37.7 \%)]$, lung cancer $[n=50(23.6 \%)]$, 


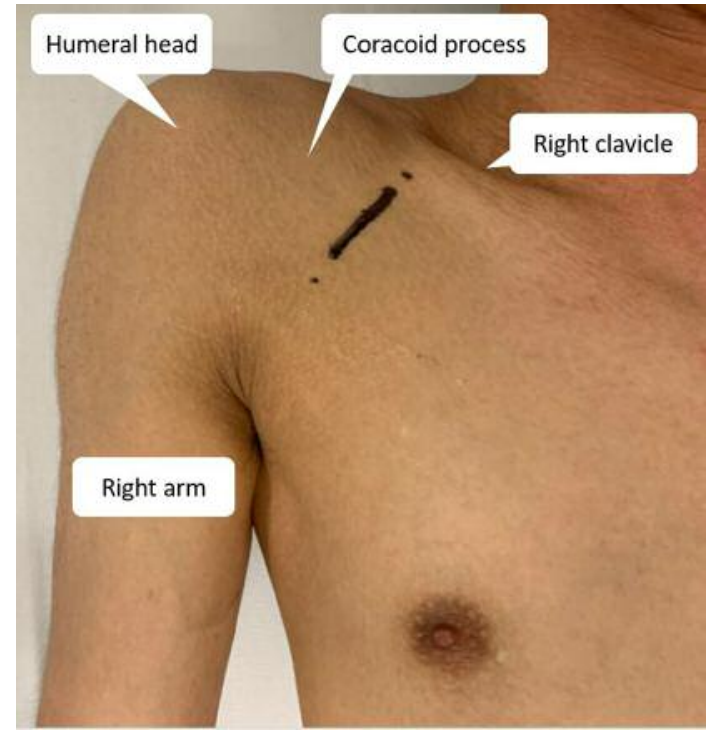

Figure 2. Skin markings along the cephalic vein route.

lymphoma/leukemia $[\mathrm{n}=21(9.9 \%)]$, otorhinolaryngologic cancer $[n=20(9.4 \%)]$, breast cancer $[n=20(9.4 \%)]$, and gynecologic cancer $[\mathrm{n}=4(1.9 \%)]$. The remaining 17 patients $(8.0 \%)$ underwent TICVAD implantation for nutritional support because of various conditions. There was no difference in the follow-up period [median (range), 287 (1952) versus 342 (1-903) days] or mortality rate during the follow-up period ( $28.2 \%$ versus $28.4 \%$ ) (Table I).

A flow chart of all cases is shown in Figure 3. Among all 212 procedures, $203(95.8 \%)$ were successful without the need to change the procedure (including 5 procedures in which the guidewire technique was used). We experienced nine unsuccessful cases (4.2\%) because the CV was too small ( 5 cases) and the catheter could not be advanced into the central vein even with the use of a guidewire (4 cases). The CV could be detected in all cases. A secondary approach was attempted in the nine unsuccessful cases. The IJV and SV puncture approach with real-time US on the same side as in the first CV approach was used in eight cases and one case, respectively. No complications were observed in any case that was changed to a secondary approach.

The mean diameter and depth of the CV measured during preoperative US were $3.3 \pm 0.9 \mathrm{~mm}(\mathrm{n}=116)$ and $11.2 \pm 5.1 \mathrm{~mm}$ $(\mathrm{n}=81)$ on the right and $3.3 \pm 1.0 \mathrm{~mm}(\mathrm{n}=62)$ and $12.1 \pm 6.0$ $\mathrm{mm}(\mathrm{n}=48)$ on the left. There was no significant difference in the diameter $(p=0.66)$ or depth $(p=0.45)$ between the two sides. The recorded venous convergence of the AV was $102 / 104(98.1 \%)$ on the right and $47 / 50(94.1 \%)$ on the left side $(p=0.33)$ (Table II).

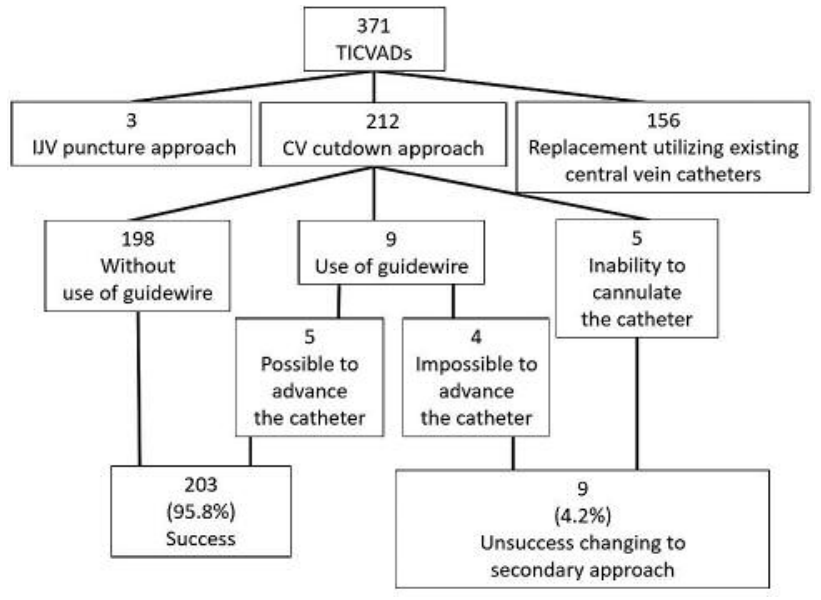

Figure 3. Flow chart of all cases. TICVADs: Totally implantable central venous access devices, IJV: internal jugular vein, CV: Cephalic vein.

The operation data of both groups are summarized in Table III. The right CV was chosen in 109 (87.9\%) patients in Group A and $77(87.5 \%)$ patients in Group B $(p=0.22)$. There was no significant difference in the duration of the operating time

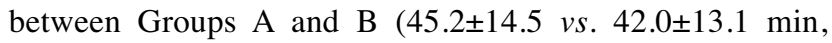
respectively; $p=0.22$ ). The completion rate was higher in Group A compared to B $(98.4 \%$ vs. $92.0 \%$, respectively; $p=0.04)$. The lack of success in Group A was due to the inability to advance the guidewire into the central vein in two cases $(1.6 \%)$. The lack of success in Group B was due to a too-small $\mathrm{CV}$ in five cases $(5.7 \%)$ and the inability to advance the guidewire into the central vein in two cases $(2.3 \%)$.

The postoperative early and late complication rates in both groups are summarized in Table IV. Wound healing disorders occurred in one $(0.8 \%)$ patient in Group A and one $(1.1 \%)$ patient in Group B. Wound infection occurred in one $(0.8 \%)$ patient in Group A. Catheter-associated bloodstream infection occurred in one $(0.8 \%)$ patient in Group A and two (2.3\%) patients in Group B. Reservoir pocket infection and catheter tip dislocation occurred in two (1.6\%) and one $(0.8 \%)$ patient in Group A, respectively. The two groups showed no significant difference in the early (1.6\% vs. $1.1 \%$, $p=0.77)$ or late complication rate $(3.2 \%$ vs. $2.3 \%, p=0.68)$.

The completion rate of $\mathrm{CV}$ cut-down for TICVAD implantation was $95.7 \%(178 / 186)$ on the right and $96.2 \%$ $(25 / 26)$ on the left side, with no significant difference between the two sides $(p>0.99)$. The early and late complication rates on the right side were $4.8 \%$ and $0.0 \%$, respectively $(p=0.60)$.

The completion rate of $\mathrm{CV}$ cut-down for TICVAD implantation was i) $95.8 \%$ (148/155) using the X-Port ${ }^{\mathrm{TM}}$ isp, ii) $100 \%(30 / 30)$ using the PowerPort ${ }^{\circledR}$ M.R.I. ${ }^{\circledR}$ isp, and iii) 92.6\% (25/27) using the MicroNeedle Port. The reasons for 
Table I. Comparison of patients' characteristics.

\begin{tabular}{|c|c|c|c|c|}
\hline & Group A $(n=124)$ & Group B $(n=88)$ & Total $(n=212)$ & $p$-Value \\
\hline Age & $65.3 \pm 11.9$ & $68.1 \pm 9.4$ & $66.9 \pm 10.6$ & 0.057 \\
\hline Gender $(\mathrm{M} / \mathrm{F})$ & $65 / 59$ & $36 / 52$ & 101/111 & 0.1 \\
\hline Body Mass Index $\left(\mathrm{kg} / \mathrm{m}^{2}\right)$ & $21.8 \pm 4.1$ & $22.6 \pm 4.5$ & 22.2 & 0.37 \\
\hline \multicolumn{5}{|l|}{ Purpose for TICVADs } \\
\hline Chemotherapy & $114(91.9 \%)$ & $81(92.0 \%)$ & $195(92.0 \%)$ & \multirow[t]{8}{*}{$>0.99$} \\
\hline Digestive tumors, $\mathrm{n}(\%)$ & $57(46.0 \%)$ & $23(26.1 \%)$ & $80(37.7 \%)$ & \\
\hline Lung cancer, n (\%) & $36(29.0 \%)$ & $14(16.0 \%)$ & $50(23.6 \%)$ & \\
\hline Lymphoma/Leukemia, n (\%) & $9(7.3 \%)$ & $12(13.6 \%)$ & $21(9.9 \%)$ & \\
\hline Otorhinolaryngologic cancer, n (\%) & $9(7.3 \%)$ & $11(12.5 \%)$ & $20(9.4 \%)$ & \\
\hline Breast cancer, $\mathrm{n}(\%)$ & $2(1.6 \%)$ & $18(20.4 \%)$ & $20(9.4 \%)$ & \\
\hline Gynecologic cancer, n (\%) & $1(0.8 \%)$ & $3(3.4 \%)$ & $4(1.9 \%)$ & \\
\hline Nutrition, $\mathrm{n}(\%)$ & $10(8.1 \%)$ & $7(8.0 \%)$ & $17(8.0 \%)$ & \\
\hline Follow-up period, days (mean, range) & $287(1-952)$ & $342(1-903)$ & $310(1-952)$ & 0.1 \\
\hline Death in the follow-up period, n (\%) & $35(28.2 \%)$ & $25(28.4 \%)$ & $60(28.3 \%)$ & 0.98 \\
\hline
\end{tabular}

Group A: surgical residents (3-5 years after graduation); Group B: experienced surgeons (>10 years after graduation); TICVADs: totally implantable central venous access devices.

Table II. Comparison of ultrasound findings on both sides.

\begin{tabular}{|c|c|c|c|c|c|c|}
\hline & & Right $(n=212)$ & & & Left $(n=212)$ & $p$-Value \\
\hline \multirow[t]{3}{*}{ The diameter of the Cephalic vein (mm) } & & $3.3 \pm 0.9(n=116)$ & & & $3.3 \pm 1.0(\mathrm{n}=62)$ & 0.66 \\
\hline & Group A & Group B & $p$-Value & Group A & Group B & $p$-Value \\
\hline & $3.3 \pm 0.9,(n=65)$ & $3.2 \pm 0.9,(n=51)$ & 0.57 & $3.4 \pm 1.0(n=29)$ & $3.3 \pm 1.0(n=33)$ & 0.9 \\
\hline \multirow[t]{3}{*}{ The depth of the cephalic vein $(\mathrm{mm})$} & & $11.2 \pm 5.1(\mathrm{n}=81)$ & & & $12.1 \pm 6.0(n=48)$ & 0.45 \\
\hline & Group A & Group B & $p$-Value & Group A & Group B & $p$-Value \\
\hline & $11.3 \pm 5.9(\mathrm{n}=45)$ & $11.2 \pm 3.8(\mathrm{n}=36)$ & 0.89 & $12.2 \pm 7.7(n=24)$ & $12.1 \pm 3.8(n=24)$ & 0.89 \\
\hline \multirow[t]{3}{*}{ Venous convergence for axially vein } & & $102 / 104(98.1 \%)$ & & & $47 / 50(94.1 \%)$ & 0.33 \\
\hline & Group A & Group B & $p$-Value & Group A & Group B & $p$-Value \\
\hline & $49 / 51(96.1 \%)$ & $53 / 53(100 \%)$ & 0.24 & $19 / 21(90.5 \%)$ & $28 / 29(96.6 \%)$ & 0.56 \\
\hline
\end{tabular}

Group A: surgical residents (3-5 years after graduation); Group B: experienced surgeons ( $>10$ years after graduation).

the lack of success using the X-Port ${ }^{\mathrm{TM}}$ isp were a too-small $\mathrm{CV}$ in five cases and the inability to advance the guidewire into the central vein in two cases, while the reason for the lack of success using the MicroNeedle Port was the inability to advance the guidewire into the central vein in two cases.

\section{Discussion}

In this study, 212 TICVAD implantation procedures were performed in 212 patients with preoperative US, and the overall completion rate was $95.8 \%$. We divided the surgeons into two groups: surgical residents and experienced surgeons. The completion rate in the surgical residents group was significantly higher compared to the experienced surgeons group. There was no difference in the duration of operating time, early complication rate, or late complication rate.

A previous retrospective study showed that TICVAD implantation, mainly attempted by the CV cut-down procedure, performed by residents alone or with help of a senior resident or an attending surgeon was safe with respect 
Table III. Operation data in both groups.

\begin{tabular}{lcc}
\hline & Group A (n=124) & Group B (n=88) \\
\hline Completion rate of & & \\
CV cutdown approach, $\mathrm{n}(\%)$ & $122(98.4 \%)$ & $81(92.0 \%)$ \\
The reason of lack of success & & $5(5.7 \%)$ \\
Thinness of the vein, $\mathrm{n}(\%)$ & $0(0.0 \%)$ & $2(2.3 \%)$ \\
Guidewire not passing, $\mathrm{n}(\%)$ & $2(1.6 \%)$ & $42.0 \pm 13.1$ \\
Operation time, min & $45.2 \pm 14.5$ & $3(3.4 \%)$ \\
Use of guidewires, $\mathrm{n}(\%)$ & $6(4.8 \%)$ & $1(1.1 \%)$ \\
Success, $\mathrm{n}(\%)$ & $4(3.2 \%)$ & $2(2.3 \%)$ \\
Failure, $\mathrm{n}(\%)$ & $2(1.6 \%)$ & 0.1 \\
\hline
\end{tabular}

Group A: surgical residents (3-5 years after graduation); Group B: experienced surgeons (>10 years after graduation); CV: cephalic vein.

Table IV. Early and late complications in both groups.

\begin{tabular}{|c|c|c|c|}
\hline & Group A $(n=124)$ & Group B $(n=88)$ & $p$-Value \\
\hline Early complication (within 7 days), n (\%) & $2(1.6 \%)$ & $1(1.1 \%)$ & $>0.99$ \\
\hline Wound healing disorder, $\mathrm{n}(\%)$ & $1(0.8 \%)$ & $1(1.1 \%)$ & \\
\hline Pneumothorax, n (\%) & $0(0.0 \%)$ & $0(0.0 \%)$ & \\
\hline Arterial puncture, $\mathrm{n}(\%)$ & $0(0.0 \%)$ & $0(0.0 \%)$ & \\
\hline Hematoma, n $(\%)$ & $0(0.0 \%)$ & $0(0.0 \%)$ & \\
\hline Wound infection, $\mathrm{n}(\%)$ & $1(0.8 \%)$ & $0(0.0 \%)$ & \\
\hline Late complication (after 8 days), n (\%) & $4(3.2 \%)$ & $2(2.3 \%)$ & $>0.99$ \\
\hline Catheter associated blood stream infection, $\mathrm{n}(\%)$ & $1(0.8 \%)$ & $2(2.3 \%)$ & \\
\hline Reservoir pocket infection, $\mathrm{n}(\%)$ & $2(1.6 \%)$ & $0(0.0 \%)$ & \\
\hline Dislocated catheter tip, $\mathrm{n}(\%)$ & $1(0.8 \%)$ & $0(0.0 \%)$ & \\
\hline
\end{tabular}

Group A: surgical residents (3-5 years after graduation); Group B: experienced surgeons (>10 years after graduation).

to major complications, but it required a longer operating time (14). In that study, 147 of 760 cases $(19.3 \%)$ required a secondary SV puncture approach. The usefulness of preoperative US for CV cut-down approach improved the completion rate and shortened the operation time in 2015, based on data from our institution (2). This is the first study to compare the safety of $\mathrm{CV}$ cut-down using preoperative US between cases performed by experienced surgeons and surgical residents.

$\mathrm{CV}$ cut-down is reportedly safe with respect to avoiding fatal complications including pneumothorax, hemothorax, and arterial injury $(2-4,8-11)$ compared to the IJV or SV puncture approaches, using the Seldinger technique with or without US. Although nine patients (4.2\%) developed complications in the present case series, no fatal complications occurred.

Although CV cut-down has a low completion rate $(80 \%$ $94 \%)(2-4,6-9,11,12,14)$, we have previously reported that preoperative US can result in a shortened operating time and have confirmed that convergence of the $\mathrm{CV}$ and $\mathrm{AV}$ can be significantly related to the low technical failure rate (2). Since the publication of our above-mentioned report, we have been routinely performing preoperative US evaluation. In the present study, IJV puncture with US was chosen as the first approach in three patients. Among these three patients, two had too-small bilateral CVs and one had a too-small left $\mathrm{CV}$ and an undetectable right $\mathrm{CV}$ on preoperative US. Cut-down was avoided because the $\mathrm{CV}$ was $<2 \mathrm{~mm}$, corresponding to the diameter of a smaller catheter $(6.0 \mathrm{Fr})$. Performing preoperative US in all cases enabled avoidance of the difficult side or of bilaterally difficult cases and thus resulted in a high completion rate. To further improve the completion rate, a guidewire can be used during CV cut-down when the catheter cannot be advanced into the central vein (10).

The EJV may also be used for the cut-down approach (5, $6,13)$. This vein reportedly has a high completion rate, a very low incidence of complications, and high patient satisfaction and compliance based on questionnaires (13). However, EJV cut-down requires two skin incisions and a subcutaneous tunnel for the catheter. We consider that $\mathrm{CV}$ cut-down has two advantages over the use of other veins. First, the first incision can be used to make a pocket for the 
reservoir in case of the surgeon needs to change to the IJV or the SV puncture approach, and this is cosmetically acceptable. Second, the incision and subcutaneous route of the catheter cannot be easily detected when the patient is wearing ordinary clothes, including short sleeves.

In this study, the surgical residents showed equivalent safety results and a higher completion rate compared to those of the experienced surgeons. No cases were incomplete because of vessel injury or an undetectable CV. Based on the preoperative evaluation of the diameter of the $\mathrm{CV}$ and convergence of the $\mathrm{CV}$ and $\mathrm{AV}$, the operator could choose the more suitable side for $\mathrm{CV}$ cut-down and avoid implantation in patients with a too-small $\mathrm{CV}$ or a $\mathrm{CV}$ without convergence with the AV.

In this study, there were no significant differences in the $\mathrm{CV}$ diameter, $\mathrm{CV}$ depth, or convergence of the $\mathrm{AV}$ and $\mathrm{CV}$ between the two sides. We selected the larger side of the $\mathrm{CV}$ for TICVAD implantation using CV cut-down. Although the optimal side for implantation of TICVADs using CV cutdown is unclear, when the $\mathrm{CV}$ diameter, $\mathrm{CV}$ depth, and convergence of the $\mathrm{AV}$ and $\mathrm{CV}$ are equivalent, we select the side same as the larger IJV or the side with the least overlap between the IJV and the carotid artery for CV cut-down. The right IJV has a much wider diameter and runs more superficially compared to the left (15). For cannulation, the right IJV is superior to the left one with respect to a shorter operation time and lower incidence of complications (16). The right side is also superior with respect to the incidence of puncture failure in the SV approach (17). Although the completion and complication rates of $\mathrm{CV}$ cut-down for both sides were equivalent in this study, some other studies have shown that left-sided insertion of central venous catheters can significantly increase the risk of thrombotic complications (18); the same is true for peripherally inserted central venous catheters (19). Furthermore, left-sided insertion of central venous catheters can be associated with a risk of azygos mal-positioning (20). Therefore, right-sided $\mathrm{CV}$ cut-down might reduce late complications; it might also reduce early complications when changing the approach to IJV or SV puncture when the diameter or overlap between the IJV and carotid artery are equivalent.

The first limitation of this case series is its retrospective design. Second, the diameter and depth of the CV were not recorded in all cases, especially in the unsuccessful cases. Further studies are needed to identify the factors associated with unsuccessful CV cut-down for TICVADs.

In conclusion, the results of this retrospective study demonstrate that $\mathrm{CV}$ cut-down with preoperative US is a safe procedure that helps to avoid fatal complications. The duration of operating time and complication rate were equivalent between surgical residents and experienced surgeons, and the completion rate was significantly higher in surgical residents. Therefore, $\mathrm{CV}$ cut-down with preoperative
US should be considered a valid approach for TICVADs for both surgical residents and experienced surgeons.

\section{Conflicts of Interest}

None.

\section{Authors' Contributions}

$\mathrm{SH}$ and RO were responsible for the study concept. All authors collaborated for the patient's medical care and approved the final manuscript for submission and agreed to be accountable for the work.

\section{Acknowledgements}

The Authors would like to thank Angela Morben, DVM, ELS, from Edanz Group (www.edanzediting.com/ac), for editing a draft of this manuscript.

\section{References}

1 Kock HJ, Pietsch M, Krause U, Wilke H and Eigler FW: Implantable vascular access systems: experience in 1500 patients with totally implanted central venous port systems. World J Surg 22(1): 12-16, 1998. PMID: 9465755.

2 Otsubo R, Hatachi T, Shibata K, Yoshida T, Watanabe H, Oikawa M, Matsumoto M, Yano $\mathrm{H}$, Taniguchi $\mathrm{H}$ and Nagayasu $\mathrm{T}$ : Evaluation of totally implantable central venous access devices with the cephalic vein cut-down approach: Usefulness of preoperative ultrasonography. J Surg Oncol 113(1): 114-119, 2016. PMID: 26645575. DOI: $10.1002 /$ jso. 24100

3 Matiotti-Neto M, Eskander MF, Tabatabaie O, Kasumova G, Bliss LA, Ng SC, Tawa NE Jr, Murphy B, Critchlow JF and Tseng JF: Percutaneous versus cut-down technique for indwelling port placement. Am Surg 83(12): 1336-1342, 2017. PMID: 29336750.

4 Biffi R, Orsi F, Pace U, Bonomo G, Monfardini L, Della Vigna P, Rotmensz N, Radice D, Zampino MG, Fazio N, de Braud F, Andreoni B and Goldhirsch A: Best choice of central venous insertion site for the prevention of catheter-related complications in adult patients who need cancer therapy: a randomized trial. Ann Oncol 20(5): 935-940, 2009. PMID: 19179550. DOI: 10.1093/annonc/mdn701

5 Kagawa T, Ueyama S, Kobayashi T, Okabayashi H, Kuroda S and Fujiwara T: A novel "shrug technique" for totally implantable venous access devices via the external jugular vein: A consecutive series of 254 patients. J Surg Oncol 115(3): 291295, 2017. PMID: 27813159. DOI: $10.1002 /$ jso.24504

6 Cavallaro G, Sanguinetti A, Iorio O, D'Ermo G, Polistena A, Avenia N, Silecchia G and De Toma G: Ultrasound-guided vein puncture versus surgical cut-down technique in totally implantable venous access devices (Tivads): A prospective comparative study on safety, efficacy and complications. Int Surg 99(4): 475-478, 2014. PMID: 25058787. DOI: 10.9738/ INTSURG-D-14-00008.1

7 Jablon LK, Ugolini KR and Nahmias NC: Cephalic vein cut-down verses percutaneous access: a retrospective study of complications of implantable venous access devices. Am J Surg 192(1): 63-67, 2006. PMID: 16769277. DOI: 10.1016/j.amjsurg.2005.11.012 
8 Di Carlo I, Cordio S, La Greca G, Privitera G, Russello D, Puleo $\mathrm{S}$ and Latteri F: Totally implantable venous access devices implanted surgically: a retrospective study on early and late complications. Arch Surg 136(9): 1050-1053, 2001. PMID: 11529829. DOI: $10.1001 /$ archsurg.136.9.1050

9 Chang HM, Hsieh CB, Hsieh HF, Chen TW, Chen CJ, Chan DC Yu JC, Liu YC and Shen KL: An alternative technique for totally implantable central venous access devices. A retrospective study of 1311 cases. Eur J Surg Oncol 32(1): 90-93, 2006. PMID: 16289481. DOI: 10.1016/j.ejso.2005.09.004

10 Chang HM, Hsieh HF, Hsu SD, Liao GS, Lin CH, Hsieh CB and Yu JC: Guidewire assisted cephalic vein cutdown for insertion of totally implantable access ports. J Surg Oncol 95(2): 156-157, 2007. PMID: 17262733. DOI: 10.1002/jso.20584

11 Povoski SP: A prospective analysis of the cephalic vein cutdown approach for chronic indwelling central venous access in 100 consecutive cancer patients. Ann Surg Oncol 7(7): 496-502, 2000. PMID: 10947017.

12 Granziera E, Scarpa M, Ciccarese A, Filip B, Cagol M, Manfredi V, Alfieri R, Celentano C, Cappellato S, Castoro C and Meroni M: Totally implantable venous access devices: retrospective analysis of different insertion techniques and predictors of complications in 796 devices implanted in a single institution. BMC Surg 14(1): 27, 2014. PMID: 24886342. DOI: 10.1186/1471-2482-14-27

13 Cavallaro G, Iorio O, Iossa A, De Angelis F, Avallone M, Massaro M, Mattia C and Silecchia G: A prospective evaluation on external jugular vein cut-down approach for TIVAD implantation. World J Surg Oncol 13(1): 243, 2015. PMID: 26264364. DOI: 10.1186/s12957-015-0663-x

14 Schreckenbach T, Münch I, Ei Youzouri H, Bechstein WO and Habbe N: The safety level of total central venous access port implantation performed by residents. J Surg Educ 76(1): 182192, 2019. PMID: 30120065. DOI: 10.1016/j.jsurg.2018.07.005
15 Ishizuka M, Nagata H, Takagi K and Kubota K: Right internal jugular vein is recommended for central venous catheterization. J Invest Surg 23(2): 110-114, 2010. PMID: 20497014. DOI: $10.3109 / 08941930903469342$

16 Sulek CA, Blas ML and Lobato EB: A randomized study of left versus right internal jugular vein cannulation in adults. J Clin Anesth 12(2): 142-145, 2000. PMID: 10818329.

17 Tsai YF, Ku YH, Chen SW, Huang WT, Lu CC and Tsao CJ: Right- and left-subclavian vein port-a-cath systems: comparison of complications. Eur Surg Res 49(2): 66-72, 2012. PMID: 22813785. DOI: $10.1159 / 000339308$

18 Debourdeau P, Farge D, Beckers M, Baglin C, Bauersachs RM, Brenner B, Brilhante D, Falanga A, Gerotzafias GT, Haim N, Kakkar AK, Khorana AA, Lecumberri R, Mandala M, Marty M, Monreal M, Mousa SA, Noble S, Pabinger I, Prandoni P, Prins MH, Qari MH, Streiff MB, Syrigos K, Büller HR and Bounameaux $\mathrm{H}$ : International clinical practice guidelines for the treatment and prophylaxis of thrombosis associated with central venous catheters in patients with cancer. J Thromb Haemost 11(1): 71-80, 2013. PMID: 23217208. DOI: 10.1111/jth.12071

19 Marnejon T, Angelo D, Abu Abdou A and Gemmel D: Risk factors for upper extremity venous thrombosis associated with peripherally inserted central venous catheters. J Vasc Access 13(2): 231-238, 2012. PMID: 22266584. DOI: 10.5301/jva.5000039

20 Haygood TM, Malhotra K, Ng C, Chasen B, McEnery KW and Chasen M: Migration of central lines from the superior vena cava to the azygous vein. Clin Radiol 67(1): 49-54, 2012. PMID: 22070939. DOI: 10.1016/j.crad.2011.05.011

Received July 28, 2019

Revised August 13, 2019

Accepted September 3, 2019 